\title{
Research Paper: \\ The Effect of Teach-Back Method on Health Promoting Lifestyle of Patients With Type 2 Diabetes
}

\author{
Rasool Raznahan $^{1}$ (D), Marhamat Farahaninia ${ }^{1^{*}}$ (D), Ezzat Jafar Jalal' ${ }^{2}$, Hamid Haghani ${ }^{3}$
}

1. Department of Community Health Nursing, School of Nursing and Midwifery, Iran University of Medical Sciences, Tehran, Iran.

2. Department of Nursing Management, School of Nursing and Midwifery, Iran University of Medical Sciences, Tehran, Iran.

3. Department of Biostatistics, School of Public Health, Iran University of Medical Sciences, Tehran, Iran.

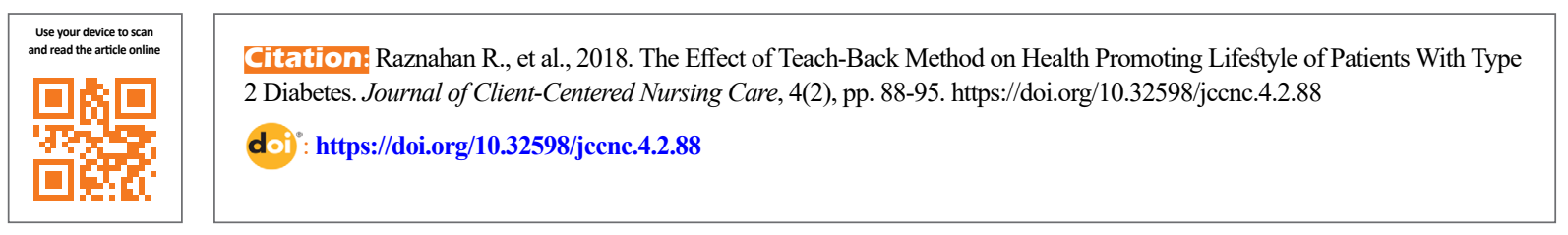

\section{(c) (i) (8)}

Funding: See Page 93

\section{Article info:}

Received: 13 Oct 2017

Accepted: 28 Jan 2018

Published: 01 May 2018

Keywords:

Teach-back method, Health promoting lifestyle, Type 2 diabetes

\begin{abstract}
A B S T R C T
Background: Diabetes is the most prevalent metabolic disease in human being. The lifestyle of this population is important and effective in the treatment process. Training is among the most basic methods of prevention, treatment and control of chronic diseases, including diabetes. This study was conducted to investigate the effect of teach-back method on health promoting lifestyle of people with diabetes.
\end{abstract}

Methods: A total of 74 eligible patients with type II diabetes were included in the study from Endocrine and Metabolism Clinic by convenience sampling method. The subjects were then assigned into the control and intervention groups. The data collection instruments consisted of a demographic data form and Health Promoting Lifestyle Profile II (HPLP-II) that were provided to the subjects before and 1 month after the training. Subjects in the intervention group received a 4-session training program by means of teach-back method. The control group received only routine programs. One month after the completion of the training sessions, the questionnaires were completed by the subjects in the 2 groups. The obtained data were analyzed by Chi-square test, Fisher Exact test, Independent t-test, Paired t-test, Mann-Whitney U test, and Wilcoxon signed-rank test, using SPSS.

Results: The obtained results suggested no significant differences between the 2 groups in terms of demographic and dependent variables, before conducting the intervention. The Mean $\pm \mathrm{SD}$ score of lifestyle was $113.67 \pm 19.55$ in the intervention group and $115.35 \pm 9.73$ in the control group, before the training, which was not significant. However, there was a difference between the Mean \pm SD score of lifestyle in the intervention group (160.45 \pm 10.53$)$ and control group (119.59 \pm 11.23$), 1$ month after the training $(\mathrm{P}<0.001)$.

Conclusion: Teach-back method is appropriate and feasible for patients with diabetes and is an effective method to improve the lifestyle of this population. This study was conducted over a 1-month period, and it is recommended that the effect of this method be investigated over longer periods of time in order to assess its long-term effects.

\section{* Corresponding Author:}

Marhamat Farahaninia, MSc.

Address: Department of Community Health Nursing, School of Nursing and Midwifery, Iran University of Medical Sciences, Tehran, Iran.

Tel: +98 (21) 43651806

E-mail: farahaninia.m@iums.ac.ir 


\section{Highlights}

- Control of diabetes comprises nutrition, exercise, blood glucose, drug therapy, and patient education.

- One of the most effective methods for improving the education is teach-back method used to better understand information.

\section{Plain Language Summary}

Diabetes is the most common chronic disease worldwide and is a major public health problem in Iran. Based on the studies, diabetes has a negative impact on the quality of life. In chronic diseases, the patient has $95 \%$ of care and treatment responsibility (personal management). This study discusses the effect of education by teach-back method on health promoting life style of patients with type 2 diabetes. Based on the results, teach-back method is effective on type 2 diabetic patients lifestyle and health program planners can use this method to promote the health and empowerment of patients with chronic diseases.

\section{Background}

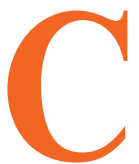

hronic diseases are the most important health issues in modern societies (Baghaei et al. 2008). Among which, diabetes is one of the most prevalent diseases and one of the leading causes of fatalities, worldwide (Caughey et al. 2010; Nathan et al. 2006). Reports indicate that there were 382 million people living with diabetes globally in 2013 and this number is expected to reach 592 million in 2035 . More than $80 \%$ of these people live in low- and middleincome countries (Reisi et al. 2016). The prevalence of diabetes in Iran is estimated to be $7.8 \%$ between the ages of 15 and 64 , and $4 \%$ to $4.5 \%$ of them suffer from type 2 diabetes (Khavasi et al. 2016).

The causes of this disease can be attributed to rapid economic growth, urbanization and changes in lifestyle, which led to a decrease in physical activity, and an increase in the obesity rate among the aging population (Alhyas et al. 2011). Generally, such changes create an inappropriate lifestyle (Mohammadi Zeidi, Pakpour Hajiagha \& Mohammadi Zeidi 2012). Overall, 70\% to $80 \%$ and $50 \%$ to $60 \%$ of fatalities, respectively in the developed and developing countries are associated with lifestyle. Therefore, it is necessary to pay more attention to the main causes of this disease, including lifestyle and human behavior (Khalkhali 2016).

The treatment of diabetes is complex and requires lifestyle modification (Khavasi et al. 2016). Type II diabetes can be managed by a modified lifestyle and an effective use of medicine (Chamberlain et al. 2016). Lifestyle consists of normal daily activities that people have in their lives, which affect their health (Henderson et al. 2006). Health promoting lifestyle includes 6 dimensions of spiritual growth, self-development, health responsibility, interpersonal relationships, stress management, exercise and physical activity, and nutrition (Rastegar et al. 2015; Shaban, Mehran \& Taghlili 2007).

The health promoting lifestyle can improve the quality of life, thereby preventing and even treating physical and mental problems (Norouzi et al. 2010; Lee et al. 2006). Thus, organized education is important as much as, or more than treatment for controlling this type of illness (Peimani et al. 2010). The main purpose of education is to develop independent self-care skills among individuals (Mohammad Pour \& Dehgan Naieri 2007). Self-care in diabetes consists of correct and timely delivery of insulin, an appropriate diet, regular exercising, identification of symptoms of high blood glucose, regular use of medications, foot care and lifestyle improvement (Vasli \& Eshghbaz 2009).

Providing effective education for people with diabetes improves treatment efficacy and treatment satisfaction, and enhances compliance with the treatment plan. This is because people with diabetes may have misunderstandings about their illness and the treatment plan. Generally, $40 \%$ to $80 \%$ of the information provided to this population is immediately forgotten, and about $50 \%$ of the information learned involves misunderstandings. Therefore, selecting the right method of education is a priority, in order to control this important component of diabetes (Funnell et al. 2009; Zakerimoghadam et al. 2010; Hemmati Maslakpak, Parizad \& Khalkhali 2012; Dunning 2013; Sadeghi et al. 2013; Brunner et al. 2010). 
The teach-back method is among the most straightforward approaches for a better understanding of information by the patients. This method increases both satisfaction of the patients, and their sense of comfort and trust in the nurse (Wilson et al. 2012). The teach-back method is used to understand and maintain information by which the trainer asks the patients to describe what they have learned, in their own words (Negarandeh et al. 2013). This helps healthcare providers identify areas requiring additional education (Kripalani et al. 2008). If the patient has not understood the subject well, the educator keeps repeating the concept until the patient fully understands the subject (Nasiri 2012). It will finally reduce the perceived misunderstanding of information by the patient (Tamura-Lis 2013).

This approach has been approved by healthcare organizations as an effective method to ensure the understanding of healthcare information (Mahramus et al. 2012). Educating patients under different conditions of health and disease is considered as one of the main responsibilities of nurses. Understanding and memorizing educational information is important in patients. Therefore, the current study aimed to investigate the effect of teach-back method on health promoting lifestyle of people with type 2 diabetes.

\section{Materials and Methods}

This was a pretest-posttest clinical trial with control group. The subjects included 74 patients with type 2 diabetes who referred to the Endocrinology and Metabolism Clinic of Gonabad University of Medical Sciences, Gonabad City, Iran in 2017. The samples were selected by convenience sampling method and according to the inclusion criteria (people over 18 years, with no mental illnesses, literate, not part of the health workforce, with no history of participation in diabetes education programs in the last 6 month, and possibility of contacting with their family members), and exclusion criteria (developing physical problems that prevents self-care), were allocated to the 2 groups of control $(n=37)$ and training $(n=37)$.

After obtaining permission from the Ethics Committee of Iran University of Medical Sciences, the relevant data were collected by referring to the Diabetes Clinic of Gonabad City. The project, research objectives and, confidentiality of personal information were explained to the study participants. The written informed consent was obtained from all samples.
In order to prevent leakage of data and isolate the 2 groups, the control group was recruited first, then the subjects of the test group were selected. Demographic information were obtained and both groups completed Health Promoting Lifestyle Profile II (HPLP-II) before conducting the intervention. Sample selection was performed at the beginning of the week and training sessions were held during the same week at the Diabetes Clinic class for individual subjects on a face-to-face basis. In addition to the routine programs of the department, a person to person training program was conducted during 4 sessions of 30 to 45 min by teach-back method. In addition, the educating manuals for diabetes were provided to the intervention group, at the end of each training session. The routine programs that included training by a physician or nurse, and departmental posters were available for the control group. The lifestyle was assessed in both groups by HPLP-II, 1 month later.

The data collection tool included the demographic data form and HPLP-II. Demographic data form included gender, age, marital status, occupation, level of education, insurance status, supplementary insurance, history of smoking, time of diabetes diagnosis, educational history and received educational programs, source of information, hospitalization history for diabetic patients, and blood glucose levels before and after the study. HPLPII consists of 52 items rated with a 4-point Likert-type scale (1: Never, 2: Sometimes, 3: Often, 4: Normally).

The tool measures health promoting lifestyle in 6 dimensions of nutrition, physical activity, health responsibility, spiritual growth, interpersonal communication and stress management. The minimum score achieved by this questionnaire is 52 and the maximum is 208 . The score of each subscale is obtained from the scores of responses to the questions of that subscale. The score of every question ranges from 1 to 4 . Validity and reliability of the Persian version of the questionnaire was assessed by Mohammadi Zeidi and colleagues. A testretest method was used to determine the reliability of the tool with a 2 -week interval.

The Cronbach $\alpha$ coefficient was used to examine the internal consistency. The Cronbach $\alpha$ value was obtained as 0.82 for the general category and 0.64 to 0.91 for the subcategories (spiritual growth: 0.64 , responsibility: 0.68 , personal relationships: 0.75 , stress management: 0.91, physical activity: 0.79, nutrition: 0.79, total: 0.82) (Mohammadi Zeidi, Pakpour Hajiagha \& Mohammadi Zeidi 2012). 
The collected data were analyzed by SPSS. Frequency distribution tables and related diagrams (for qualitative data) and mean and standard deviation (for quantitative data) were used to describe the results. The KolmogorovSmirnov test was used to assess the normality of the data. Paired sample $t$ test and Independent $t$ test were applied to compare the mean scores and normal data. Non-parametric Mann-Whitney U test and Wilcoxon signed-rank test were used for analyzing the non-normal data. The significance level was considered 0.05 for all tests.

\section{Results}

The obtained data suggested that the control and intervention groups were homogeneous in terms of demographic information. The mean score of age was 47.08 years in the intervention group and 43.54 years in the control group, with the mean age of 45.31 years for both. The majority of subjects were married, housekeepers, held diploma degree, and had a history of diabetes for longer than 2 years (Table 1).

Table 1. Demographic information of type 2 diabetic patients in control and intervention groups

\begin{tabular}{|c|c|c|c|c|}
\hline \multirow[t]{2}{*}{ Group } & \multirow{2}{*}{ Variable } & Intervention & Control & \multirow{2}{*}{ Test Results } \\
\hline & & \multicolumn{2}{|c|}{ No. (\%) } & \\
\hline \multirow{3}{*}{ Age, $y$} & $20-39$ & $11(29.8)$ & 15 (40.6) & $t=1.4$ \\
\hline & $40-59$ & $19(51.3)$ & 17 (45.9) & $\mathrm{df}=72$ \\
\hline & $60-70$ & $7(18.9)$ & $5(13.5)$ & $P^{*}=0.16$ \\
\hline \multirow{3}{*}{ Gender } & Male & $18(48.6)$ & $18(48.6)$ & $\chi^{2}=0$ \\
\hline & & & & $d f=1$ \\
\hline & Female & $19(51.4)$ & 19 (51.4) & $\mathrm{P}^{* *}=1$ \\
\hline \multirow{3}{*}{ Marital status } & Married & $30(81)$ & $23(62.1)$ & $\chi^{2}=3.2$ \\
\hline & & & & $d f=1$ \\
\hline & Single & $7(19)$ & 14 (37.9) & $P^{* *}=0.07$ \\
\hline \multirow{7}{*}{ Employment status } & Employed & $3(8.2)$ & $4(10.8)$ & \\
\hline & Self-employment & $8(21.6)$ & $9(24.3)$ & \\
\hline & Retired & $5(13.5)$ & $3(8.2)$ & \\
\hline & & & & $\mathrm{P}^{* * *}=0.96$ \\
\hline & Housekeeper & $12(32.4)$ & $11(29.7)$ & \\
\hline & Unemployed & $5(13.5)$ & $7(18.9)$ & \\
\hline & Worker & $4(10.8)$ & $3(8.1)$ & \\
\hline \multirow{5}{*}{ Education } & Illiterate & $6(16.2)$ & $6(16.2)$ & \\
\hline & Primary school & $9(24.4)$ & $9(24.4)$ & $\chi^{2}=4.98$ \\
\hline & Secondary school & $8(21.6)$ & $7(18.9)$ & $d f=4$ \\
\hline & Diploma & $12(32.4)$ & 7 (18.9) & $P^{* *}=0.28$ \\
\hline & Undergraduate or higher degree & $2(5.4)$ & $8(21.6)$ & \\
\hline \multirow{3}{*}{ History of diabetes } & 6 month to 2 years & $6(16.3)$ & $8(21.7)$ & $\chi^{2}=0.45$ \\
\hline & $2-4$ years & $13(35.1)$ & $11(29.7)$ & $\mathrm{df}=2$ \\
\hline & $>4$ years & $18(48.6)$ & $18(48.6)$ & $\mathrm{P}^{* *}=0.79$ \\
\hline
\end{tabular}

* Independent $\mathrm{T}$ test; ${ }^{* *}$ Chi-square test; ${ }^{* * *}$ Fischer's Exact test 
Table 2. Numerical indicators of the health promoting lifestyle of people with type 2 diabetes in the control and intervention groups

\begin{tabular}{|c|c|c|c|}
\hline \multirow{2}{*}{ Time } & Intervention Group & Control Group & \multirow{2}{*}{ Independent T-Test Results } \\
\hline & \multicolumn{2}{|c|}{ Mean \pm SD } & \\
\hline Before training & $113.67 \pm 19.55$ & $115.35 \pm 9.73$ & $t=0.46, d f=72, P=0.64$ \\
\hline One month after training & $160.45 \pm 10.53$ & $119.59 \pm 11.23$ & $t=16.11, d f=72, P<0.001$ \\
\hline Paired $t$ test results & $t=12.82, d f=36, P<0.001$ & $t=1.70, d f=36, P=0.09$ & \\
\hline
\end{tabular}

According to the Independent $t$ test, the Mean \pm SD scores of health promoting lifestyle were $113.67 \pm 19.55$ in the intervention group and $115.35 \pm 9.73$ in the control group, before the training. There were no significant differences in terms of lifestyle score before training, between the 2 groups $(\mathrm{P}=0.642)$. The Mean $\pm \mathrm{SD}$ scores of the subjects' lifestyle were $160.45 \pm 10.53$ in the training group and $119.59 \pm 11.23$ in the control group, 1 month after the training.

According to the Independent $\mathrm{t}$ test, lifestyle score was significantly higher in the intervention group than

Table 3. Numerical indicators of the health promoting lifestyle dimensions in people with type 2 diabetes in the control and intervention groups

\begin{tabular}{|c|c|c|c|c|}
\hline \multirow{4}{*}{$\begin{array}{c}\text { Spiritual development } \\
\text { and self-development } \\
(9-36)\end{array}$} & Int & on Group & Control Group & \multirow{3}{*}{$\begin{array}{l}\text { Independent } \mathrm{T} \text {-Test Results } \\
t \mathrm{t}=1.2, \mathrm{df}=72, \mathrm{P}=0.23\end{array}$} \\
\hline & \multicolumn{3}{|c|}{ Mean \pm SD } & \\
\hline & Before & $23.2 \pm 6.3$ & $21.7 \pm 4.4$ & \\
\hline & After & $28.4 \pm 3.2$ & $22.3 \pm 3.5$ & $t=7.64, d f=72, P<0.001$ \\
\hline Paired t-test result & \multicolumn{2}{|c|}{$t=4.64, d f=36, P<0.001$} & $t=0.79, d f=36, P=0.43$ & \\
\hline \multirow{2}{*}{$\begin{array}{l}\text { Responsibility for } \\
\text { health }(9-36)\end{array}$} & Before & $19.4 \pm 5.7$ & $20.3 \pm 4.3$ & $t=0.72, d f=72, P=0.46$ \\
\hline & After & $27.5 \pm 2.2$ & $21 \pm 4$ & $\mathrm{t}=8.51, \mathrm{df}=72, \mathrm{P}<0.001$ \\
\hline Paired t-test result & \multicolumn{2}{|c|}{$t=7.4, d f=36, P<0.001$} & $t=0.64, d f=36, P=0.52$ & \\
\hline \multirow{2}{*}{$\begin{array}{l}\text { Interpersonal rela- } \\
\text { tions }(9-36)\end{array}$} & Before & $20.5 \pm 6$ & $22.1 \pm 4.4$ & $t=1.26, d f=72, P=0.20$ \\
\hline & After & $27 \pm 3.3$ & $22.2 \pm 3.5$ & $t=5.97, d f=72, P<0.001$ \\
\hline Paired $t$ test result & \multicolumn{2}{|c|}{$t=5.57, d f=36, P<0.001$} & $t=0.11, d f=36, P=0.91$ & \\
\hline \multirow{2}{*}{$\begin{array}{l}\text { Stress management } \\
\qquad(8-32)\end{array}$} & Before & $18.2 \pm 3.6$ & $18.9 \pm 3.9$ & $t=0.79, d f=72, P=0.42$ \\
\hline & After & $25.4 \pm 3.6$ & $17.7 \pm 3.2$ & $t=9.29, d f=72, P<0.001$ \\
\hline Paired $t$ test result & \multicolumn{2}{|c|}{$t=8.11, d f=36, P<0.001$} & $t=1.47, d f=36, P=0.14$ & \\
\hline \multirow{2}{*}{$\begin{array}{c}\text { Exercise and physical } \\
\text { activity }\end{array}$} & Before & $14.8 \pm 5.5$ & $14.8 \pm 4$ & $t=0.45, d f=72, P=0.74$ \\
\hline & After & $25.4 \pm 3.6$ & $15.9 \pm 3.5$ & $t=11.37, d f=72, P<0.001$ \\
\hline Paired $t$ test result & \multicolumn{2}{|c|}{$t=9.76, d f=36, P<0.001$} & $t=1.08, d f=36, P=0.28$ & \\
\hline \multirow{2}{*}{ Nutrition (9-36) } & Before & $20 \pm 3.9$ & $19.3 \pm 1.6$ & $\mathrm{t}=0.80, \mathrm{df}=72, \mathrm{P}=0.79$ \\
\hline & After & $26.6 \pm 3.5$ & $20.3 \pm 2.7$ & $t=8.49, d f=72, P<0.001$ \\
\hline Paired $\mathrm{t}$ test result & \multicolumn{2}{|c|}{$t=7.93, d f=36, P<0.001$} & $t=5.7, d f=36, P<0.001$ & \\
\hline
\end{tabular}


control group $(\mathrm{P}<0.001)$. Also, the paired sample $t$ test revealed a significant difference between lifestyle in the intervention group before and 1 month after training, which significantly increased after training $(\mathrm{t}=1.702$, $\mathrm{P}=0.097$ ) (Table 2).

Considering the results of Independent $t$ test, there was no significant differences between the 2 groups in terms of mean scores of lifestyle before training. However, there was a significant difference between the groups, 1 month after receiving the training and the mean scores were significantly higher in the intervention group $(\mathrm{P}<0.001)$. In addition, according to the result of the paired $t$ test in the intervention group, there was a significant difference between the mean scores of lifestyle dimensions before and 1 month after training, and it was significantly higher 1 month later $(\mathrm{P}<0.001)$. Meanwhile, there was no significant differences in the control group, but significant differences were found in them in terms of their nutrition $(\mathrm{P}<0.001)$ (Table 3$)$.

\section{Discussion}

The obtained results suggested that the mean scores and standard deviation of lifestyle increased in the intervention group after implementing the teach-back method. However, there was no significant differences between the mean and standard deviation scores in the control group, before and after conducting the teachback method.

De Greef et al. (2011) aimed to investigate the effects of teaching lifestyle by call center support for improving the physical activities and exercises in people with type 2 diabetes. They reported that training significantly increased physical activity and decreased inactivity in the intervention group over a period of 24 weeks and at 1 year follow-up, which is in line with the results of this study. Likewise, Atash-Zadeh Shourideh explored the effects of implementing the Family-Centered Empowerment Model on lifestyle, self-efficacy and HbAlc in diabetic patients.

They concluded that, the lifestyle and self-efficacy scores of both groups increased and HbAlc decreased, with higher, consistent and significant changes after the intervention in the experimental group, compared to the control group (Atashzadeh Shoorideh et al. 2017). (Li et al. (2008) also reported the efficacy of these interventions and documented that lifestyle interventions was effective in the development and control of diabetes, especially type 2 diabetes. Lin \& Wang (2013) investigated the theoretical-critical model and believed that changing the behavior (lifestyle) would improve behavior, modify lifestyle, promote self-esteem, create a friendly environment and support system, in type 2 diabetic patients.

In their study on the effect of behavioral training on lifestyle in type 2 diabetic patients, Tghzadeh, Bigheli and Mohtasami (2014) found that training increases the knowledge as well as attitude and practice of subjects in terms of nutritional habits and physical activity. The results of their research also revealed that the self-care behaviors were significantly increased in the intervention group. Baker et al. (2011) also found that lifestyle modification in controlling diabetes was more successful than drug intervention. Nasrabadi et al. (2010). investigated the effects of education on the lifestyle of patients with ischemic heart disease. They reported that behavioral change programs reduce the adverse effects of pharmacotherapy, which can be considered as a method to improve lifestyle.

Health education and appropriate corrective and behavioral approaches are among the most effective methods to prevent and control diabetes. These trainings focus on raising awareness, enhancing the motivation and skills of individuals to better collaborate on the implementation of prescribed therapies and improving their active participation in self-care with the help of other family members (Brunner et al. 2010). Considering the effectiveness of such interventions, tech-back method is appropriate to improve the lifestyle of people with type 2 diabetes. This study was conducted over a 1-month period, and it is recommended that the effect of this method be investigated over longer periods of time, in order to assess its long-term effects. It is also recommended to assess the effect of this method on other chronic diseases.

\section{Ethical Considerations}

\section{Compliance with ethical guidelines}

This article was licensed by the Ethics Committee of Iran University of Medical Sciences at IR.IUMS.FMD. REC with No. 1396.9511690003 and registered under IRCT20171027037036N2 code at the Iranian Center for Clinical Trials.

\section{Funding}

This article is the result of a Master thesis of Rasool Raznahan in Iran University of Medical Sciences and sponsored by the University. 


\section{Authors contributions}

The authors contributions is as follows: Conceptualization: Rasool Raznahan, Marhamat Farahaninia and Ezzat Jafar Jalal; Methodology: Rasool Raznahan, Marhamat Farahaninia and Hamid Haghani; Investigation: Rasool Raznahan; Writing original draft: Rasool Raznahan, Marhamat Farahaninia; Writing-review \& editing, Rasool Raznahan, Marhamat Farahaninia, and Supervision: Marhamat Farahaninia.

\section{Conflict of interest}

The authors declare no conflict of interest.

\section{Acknowledgements}

We appreciate Faculty of Nursing and Midwifery of Iran University of Medical Sciences, undergraduate nursing students, authorities of Allameh Bohlul Gonabadi Hospital, and all individuals and patients who helped us with this research.

\section{References}

Alhyas, L., et al., 2011. Prevalences of overweight, obesity, hyperglycaemia, hypertension and dyslipidaemia in the Gulf: Systematic review. Journal of The Royal Society of Medicine, 2(7), pp. 1-16. [DOI:10.1258/shorts.2011.011019] [PMID] [PMCID]

Atashzadeh_Shoorideh, H., et al., 2017. [The effect of familycentered empowerment model on the life style, self-efficacy and $\mathrm{HbA} 1 \mathrm{C}$ of diabetic patients (Persian)]. Iranian Journal of Endocrinology and Metabolism, 19(4), pp. 244-51.

Baghaei, P., et al., 2008. [Self-care behaviour of patients with diabetes in Kashan centers of diabetes (Persian)]. Feyz Journal of Kashan University of Medical Sciences, 12(1), pp. 88-93.

Baker, M. K., et al., 2011. Behavioral strategies in diabetes prevention programs: A systematic review of randomized controlled trials. Diabetes Research and Clinical Practice, 91(1), pp. 1-12. [DOI:10.1016/j.diabres.2010.06.030] [PMID]

Brunner, L. S., et al., 2010. Brunner E Suddarth's textbook of medicalsurgical nursing. Philadelphia: Lippincott Williams \& Wilkins.

Caughey, G. E., et al., 2010. Comorbidity in the elderly with diabetes: Identification of areas of potential treatment conflicts. Diabetes Research and Clinical Practice, 87(3), pp. 385-93. [DOI:10.1016/j.diabres.2009.10.019] [PMID]

Chamberlain, J. J., et al., 2016. Diagnosis and management of diabetes: Synopsis of the 2016 American Diabetes Association standards of medical care in diabetes. Annals of Internal Medicine, 164(8), pp. 542-52. [DOI:10.7326/M15-3016] [PMID]

De greef, K. P., et al., 2011. The effects of a pedometer-based behavioral modification program with telephone support on physical activity and sedentary behavior in type 2 diabetes patients. Patient Education and Counseling, 84(2), pp. 275-9. [DOI:0.1016/j.pec.2010.07.010]

Dunning, T., 2013. Care of people with diabetes: A manual of nursing practice. Hoboken: John Wiley \& Sons.

Funnell, M. M., et al., 2009. National standards for diabetes selfmanagement education. Diabetes Care, 32(Suppl. 1), pp. S87S94. [DOI:10.2337/dc09-S087]

Hemmati Maslakpak, M., Parizad, N. \& Khalkhali, H., 2012 [The effect of tele-education by telephone and short message service on glycaemic control in patient with type 2 diabetes (Persian)]. Journal of Urmia Nursing and Midwifery Faculty, 10(4), pp. $580-8$.

Henderson, D., et al., 2006. Nursing EDGE: Evaluating delegation guidelines in education. International Journal of Nursing Education Scholarship, 3(1), p. 1197. [DOI:10.2202/1548923X.1197] [PMID]

Khalkhali, H. R., 2016. [The effect of conseling on health promotion behaviors in diabetic mothers referred to motahhari hospital of Urmia at 2016 (Persian)]. Journal of Urmia Nursing and Midwifery Faculty, 14(9), pp. 757-66.

Khavasi, M., et al., 2016. [The effect of peer education on diabetes self-efficacy in patients with type 2 diabetes: A randomized clinical trial (Persian)]. Journal of Knowledge \& Health, 11(2), pp. 67-74.

Kripalani, S., et al., 2008. Clinical research in low-literacy populations: Using teach-back to assess comprehension of informed consent and privacy information. IRB: Ethics $\mathcal{E}$ Human Research, 30(2), pp. 13-9. [PMID]

Lee, T. W., Ko, I. S. \& Lee, K. J., 2006. Health promotion behaviors and quality of life among community-dwelling elderly in Korea: A cross-sectional survey. International Journal of Nursing Studies, 43(3), pp. 293-300. [DOI:10.1016/j.ijnurstu.2005.06.009] [PMID]

Li, G., et al., 2008. The long-term effect of lifestyle interventions to prevent diabetes in the China Da Qing Diabetes Prevention Study: A 20-year follow-up study. The Lancet, 371(9626), pp. 1783-9. [DOI:10.1016/S0140-6736(08)60766-7]

Lin, S. P. \& wang, M. J., 2013. Applying the transtheoretical model to investigate behavioural change in type 2 diabetic patients. Health Education Journal, 72(2), 189-202. [DOI:10.1177/0017896912437495]

Mahramus, T., et al., 2012. 4. Evaluation of an educational intervention, utilizing simulation and a Teach Back (TB) method, to increase nurses' knowledge and retention of Heart Failure (HF) Self-Management (SM) principles. The Journal of Acute and Critical Care, 41(4), p. 413. [DOI:10.1016/j.hrtlng.2012.04.017]

Mohammad Pour, A. \& Dehgan Naieri, N., 2007. [The survey of the patient educational need on discharge phase in Gonabad health and treatment centers (Persian)]. Quarterly of Horizon of Medical Sciences, 12(4), pp. 34-9.

Mohammadi Zeidi, I., Pakpour Hajiagha, A. \& Mohammadi Zeidi, B., 2012. [Reliability and validity of Persian version of the health-promoting lifestyle profile (Persian)]. Journal of Mazandaran University of Medical Sciences, 21(1), pp. 102-113.

Moore, R. J., 2013. Handbook of pain and palliative care. New York: Springer-Verlag New York. 
Nasiri, A., 2012. Effect of an educational plan based on teachback method on hemodialysis patients' self-care deficits. Modern Care Journal, 9(4), pp. 344-54.

Nasrabadi, T., et al., 2010. [The effect of education on life style among patients suffering from ischemic heart disease (Persian)]. Journal of Mazandaran University of Medical Sciences, 20(79), pp.72-9.

Nathan, D. M., et al., 2006. Management of hyperglycaemia in type 2 diabetes: A consensus algorithm for the initiation and adjustment of therapy. Diabetologia, 49(8), pp. 1711-21. [DOI:10.1007/s00125-008-1157-y]

Negarandeh, R., et al., 2013. Teach back and pictorial image educational strategies on knowledge about diabetes and medication/dietary adherence among low health literate patients with type 2 diabetes. Primary Care Diabetes, 7(2), pp. 111-8. [DOI:10.1016/j.pcd.2012.11.001] [PMID]

Norouzi, A., et al., 2010. [Determinants of physical activity based on Health Promotion Model (HPM) in diabetic women of Karaj diabetic institute (Persian)]. Iranian South Medical Journal, 13(1), pp. 41-51.

Rastegar, M., et al., 2015. Health-promoting lifestyle and its related factors among health volunteers Mashhad in 2015. Journal of Torbat Heydariyeh University of Medical Sciences, 3(3), pp. 48-55.

Peimani, M., et al., 2010. Knowledge, attitude and practice of physicians in the field of diabetes and its complications; A pilot study. Journal of Diabetes and Metabolic Disorders, 9, pp. 10-7.

Reisi, M., et al., 2016. [Communicative and critical health literacy and self-care behaviors in patients with type 2 diabetes (Persian)]. Iranian Journal of Diabetes and Metabolism, 14(3), pp. 199-208.

Sadeghi, M., et al., 2013. [Comparison of the impact of education based on the empowerrment model and family-center empowerrment model on knowledge and metabolic control of patients with type 2 diabetes mellitus (Persian)]. Journal of Nursing Education, 2(3), pp. 18-27.

Shaban, M., Mehran, A. \& Taghlili, F., 2007. [Relationship between perception of health concept and health promoting behaviors: A comparative study among Tehran university medical and non-medical Students (Persian)]. Journal of Hayat, 13(3), pp. 27-36.

Shojaeizadeh, D., et al., 2008. [Comparison of diabetes type II Patients life style effective factors with that of healthy people (Persian)]. The Journal of Shahid Sadoughi University of Medical Sciences, 16(2), 71-9.

Tamura Lis, W., 2013. Teach-back for quality education and patient safety. Urologic Nursing, 33(6), p. 267. [DOI:10.7257/1053816X.2013.33.6.267]

Tghzadeh, M. E., bigheli, Z. \& mohtasami, T., 2014. [The Effect of educational modification behavior in lifestyle of diabetic patients (Persian)]. Scientific Journal Management System, 3(1), pp. 30-45.

Vasli, P. \& Eshghbaz, F., 2009. [Survey condition regarding selfcaring of children suffering from diabetes type 1 and It's relation with family reaction (Persian)]. Journal of Mazandaran University of Medical Sciences, 19(69), pp. 38-44.

Wilson, F. L., et al., 2012. Using the teach-back method to increase maternal immunization literacy among low-income pregnant women in Jamaica:A pilot study. Journal of Pediatric Nursing, 27(5), pp. 451-9. [DOI:10.1016/j.pedn.2011.05.004] [PMID]

Zakerimoghadam, M., et al., 2010. [Effect of patient education about pain control on patients' anxiety prior to abdominal surgery (Persian)]. Journal of hayat, 15(4), pp. 13-22. 